\title{
V001 NEW GEOPHYSICAL METHOD FOR DETERMINING THE CHARACTER OF RESERVOIR SATURATION WITH OIL, GAS AND WATER
}

\author{
B.P. DYAKONOV ${ }^{1}$ and A.K. TROYANOV ${ }^{2}$ \\ 'VNIIGeoinformsystem \\ ${ }^{2}$ Institute of Geophysics of the Russian Academy of Sciences, Institute of Geophysics, Amundsena 100 , \\ 620016 Ekaterinburg, Russia
}

High rates of oil production cannot be attained without application of numerous means and methods of intensifying inflows and raising oil production of layers.

Pumping water into a productive coily layer in one of the technological methods.

In this connection during the process of exploitation of the layer (deposit) there arises the recessity of control over technical condition of boreholes and a change in the rature of collectors' oil saturation in time.

The difference of oils as per their viscosity and saturation with gas suggests various approaches to evaluating the charocter of reservoir saturations.

High-viscosity oils are characterized by a spectrum of geoaconstic noises with maximum freguencies of $300-400 \mathrm{~Hz}$ CGremikhinskoye field, Udmurtia;Karazhanbas fielid,kazakhstan).Estinates of the effective cuefficient of absorption for high-viacosity oil and water saturated zones.indicates that this parameter may be used to determine the character of the reservoir saturation.

$$
\text { Low-viscosity with a gas factor of up to } 20-30 \text { cu. m. thon }
$$


and higer have, as a rule, a discrete spectrum of geoacoustic signals with high frequencies of 1.0 to $1.8 \mathrm{KHz}$ (Kiengopskoye field. Western Siberia;Kalamkas field,Kazakhstan; Barsukouskoye field, Western Siberia). Gas saturated reservoirs are characterized by a continuous spectrum of geoacoustic noises in a frequency range of $20-4500 \mathrm{~Hz}$. Water saturated reservoirs are characterized by the spectra of their geoacoustic noises being limited by maximum frequencies of $500-600 \mathrm{~Hz}$.

Thus, the character of reservoir saturations with oil,gas and water are desribed by spectral parameters og geoacoustic noises.

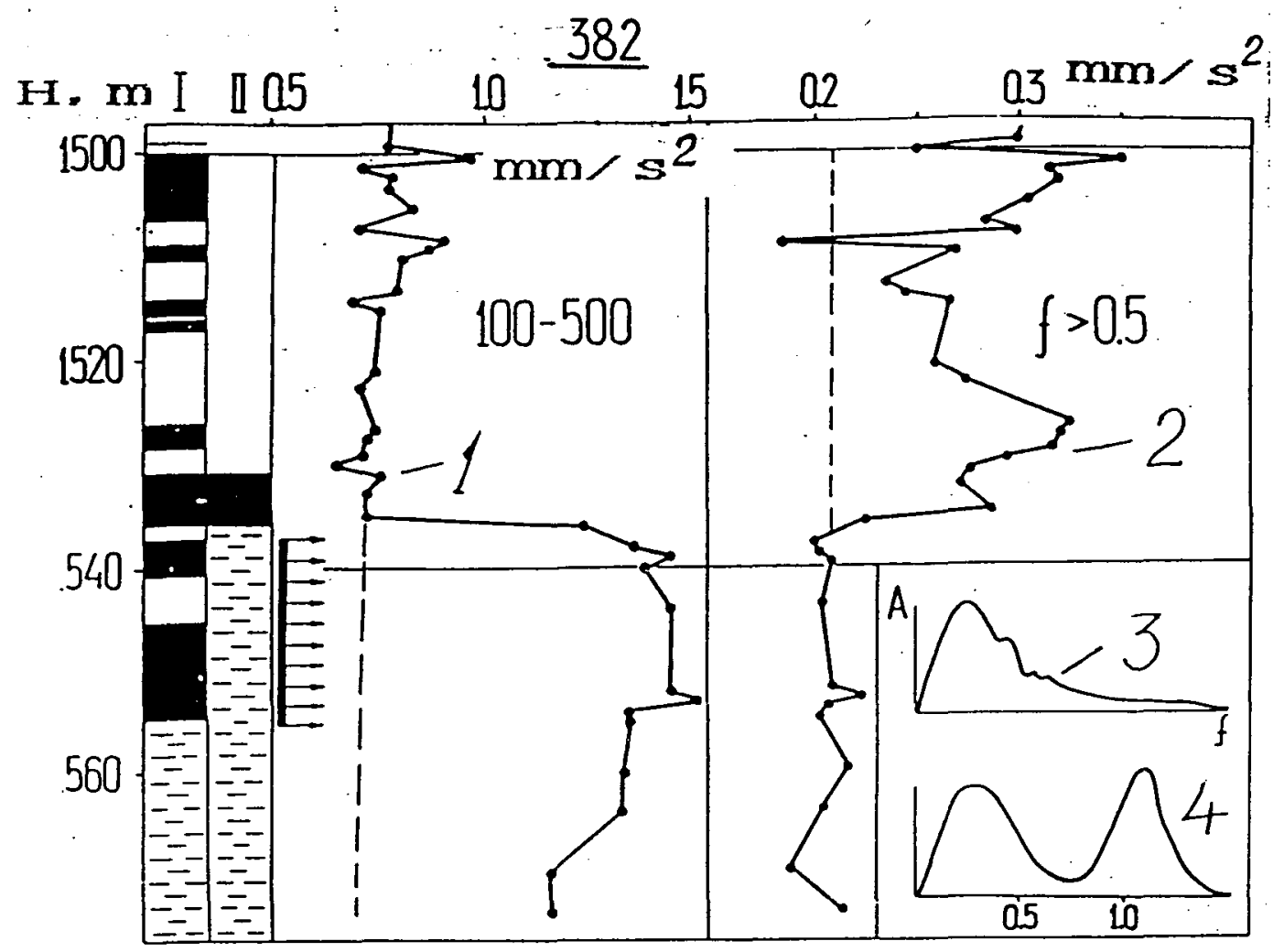

Fig. 1. The detection of an interval of water encroachment 1.2 -SAN diagrans,3,4- the spectra of water - satu rated and oil-aturated seans.

The following informative parameters of Gan are offered for 
USE:

- distribution of integral amplitude level both uthin the frequency band of $100-500 \mathrm{~Hz}$ and $500-2500 \mathrm{~Hz}$ for each of the three inducers $(X, Y, Z)$;

- relation of signals" amplitudinal level from the vertical induser to signals' amplitudes from the horizontal induser within the frequency band of $100-500 \mathrm{~Hz}$ (parameter $Z / X$ or $Z / Y$ );

- relation of signals from the horizontal indusers within the frequency range of $500-2500 \mathrm{~Hz}$ (parameter $\mathrm{K} / \mathrm{Y}$ );

- relation of signals' level within the frequency range of $500-2500 \mathrm{~Hz}$ to the signals' amplitudes within the frequency band of $100-500 \mathrm{~Hz}$ for each of the three inducers iparameters $\mathrm{Nx}, \mathrm{Ny}, \mathrm{Nz}$;

- relation of sigrals' amplitudes with the frequency band of 500-2500 Hz registered by the vertical and horizontal inducers (pardieter $Z /{ }^{\prime}$ or $\left.Z / Y\right)$;

- amilitude-frequency spectra of signals.

For prartical purposes there used those informative Son parameters that are required for solution of a conorete geological task.

The use of san three-component measurements allows to solve the following tasks:

1. To reveal non - hermetic character of a casing colmin and behind-tube circulations in production boreholes:

2.To determine the intervals of fluids movement along the layer:

3. To stuty the profile of inflow in a perforated interval a $a$ casing rolumn:

4. To find behind-tube circulations hefore nerforation and after repairs: 
5. To determine the nature of gas, water and oil saturation of layers not opened by perforation.

An example of practical realisation of SAN measurements for evaluation of the nature of collectors' saturation in borehole 382 (Udmurtia) is given on Fig.1 . The section of productive stratum opened by a borehole in 1975 is shown in column I. The SAN investigation have been carried out after the borehole exploitation during II vears.Correlation of signals in the frequency bands of $100-500 \mathrm{~Hz}$ (curve 1) and $500-2500 \mathrm{~Hz}$ (curve 2) gives reason to consider two low oil layers, opened by perforation in 1975, filled with water (column II). It is true, the spectrum of water-saturated layer (3) does not show high-frequency signals $\left(>1 \mathrm{kHz}\right.$ ), specific for the oils spectrum with a gas factor $17-27 \mathrm{~m}^{3}$ T. Water-filling of oil layers and a rise of water-oil contact up to the of mark of $1535 \mathrm{~m}$ have been checked and proved by testing in the process of work by oil and gas production department "Izhevskloil".

At present,oil-borehole equipment and the methodology of studying geoacoustical noises, developed at the Institute of Geophysics of the Urais Branch of the Russian Academy of Sciences,are used to control the exploitation of oil reservoirs. 